\title{
LA FILOSOFÍA JURÍDICA "PROSOPOLÓGICA" DE JEAN-MARC TRIGEAUD ANTE LAS INTERPELACIONES CONTEMPORÁNEAS DE LA BIOÉTICA \\ EL CASO DEL “DIAGNÓSTICO GENÉTICO PREIMPLANTATORIO”
}

\author{
Jean-Marc Trigeaud's "prosopological" legal philosophy in the face of \\ contemporary bioethical questions \\ The case of the "Preimplantation Genetic Diagnosis" \\ La filosofia giuridica "prosopologica" di Jean-Marc Trigeaud di fronte \\ alle interpellazioni contemporanee della bioetica
}

Renato Rabbi-Baldi Cabanillas ${ }^{1}$

Para citar este artículo:

Rabbi-Baldi Cabanillas, R. (2020). “La filosofía jurídica 'prosopológica' de jean-marc trigeaud ante las interpelaciones contemporáneas de la bioética”.

Prudentia Iuris, N. Aniversario, pp. 365-376.

DOI: https://doi.org/10.46553/prudentia.aniversario.2020.pp.365-376

Resumen: El presente artículo desarrolla algunas consideraciones en torno del pensamiento del antiguo catedrático de la Universidad de Burdeos, Jean-Marc Trigeaud, quien, a lo largo de su extensa y prolífica producción científica, asume que el único modo de responder con cierta plausibilidad a los desafíos que presenta la sociedad contemporánea es arraigar en una filosofía jurídica por él denominada -acaso provocadoramente- "prosopológica", es decir, en una concepción que dé cuenta del ser humano "desnudo", esto es,

1 Profesor Titular de Teoría General y Filosofía del Derecho, Universidad de Buenos Aires, Buenos Aires, Argentina y de Introducción al Derecho, Universidad Católica de Salta, Salta, Argentina. Correo electrónico: renatorb@fibertel.com.ar 
en tanto que tal, sin ninguno de los ropajes que lo caracterizan de ordinario (sexo, nacionalidad, religión, capacidad, condiciones físicas, cultura, etc.).

Palabras clave: Persona; Derechos Humanos; Dignidad; Bioética; Diagnóstico genético preimplantatorio.

\begin{abstract}
This article develops some considerations about the work of the former professor at the University of Bordeaux, Jean-Marc Trigeaud, in his extensive and prolific scientific production, Trigeaud assumes that the only way to respond with some plausibility to the challenges that contemporary society presents is to take root in a legal philosophy that he calls -perhaps provocatively- "prosopological", that is, in a conception that accounts for the "naked" human being, that is, as such, without any of the clothing that characterizes it ordinarily (sex, nationality, religion, ability, physical conditions, culture, etc.).
\end{abstract}

Keywords: Person; Human Rights; Dignity; Bioethics; Preimplantation genetic diagnosis.

Sommario: Questo articolo sviluppa alcune considerazioni attorno al pensiero dell'ex professore all'Università di Bordeaux, Jean-Marc Trigeaud, che in tutta la sua vasta e prolifica produzione scientifica, presume che l'unico modo per rispondere con una certa plausibilità alle sfide che la società contemporanea presenta è di radicarsi in una filosofia giuridica da lui chiamata -forse provocatoriamente- "prosopologica", cioè in una concezione che rende conto dell'essere umano "nudo", cioè, come tale, privo di nessuna delle abiti che normalmente lo caratterizzano (sesso, nazionalità, religione, abilità, condizioni fisiche, cultura, ecc.).

Parole chiave: Persona; Diritti Umani; Dignità; Bioetica; Diagnosi genetica preimpianto.

\title{
I. Introducción
}

Agradezco a Prudentia Iuris el convite que se me ha formulado con motivo de su $40^{\circ}$ aniversario. Constituye un honor participar en este número homenaje a una publicación que ha tenido, entre sus objetivos, la defensa irrestricta del ser humano, en tanto fundamento de la coexistencia social y, por añadidura, del Derecho. Dentro de ese espíritu, efectuaré algunas consideraciones en torno del pensamiento del antiguo catedrático de la Universidad de Burdeos, Jean-Marc Trigeaud, quien a lo largo de su extensa y 
prolífica producción científica, asume que el único modo de responder con cierta plausibilidad a los desafíos que presenta la sociedad contemporánea es arraigar en una filosofía jurídica por él denominada -acaso provocadoramente- "prosopológica", es decir, en una concepción que dé cuenta del ser humano "desnudo", esto es, en tanto que tal, sin ninguno de los ropajes que lo caracterizan de ordinario (sexo, nacionalidad, religión, capacidad, condiciones físicas, cultura, etc.).

A su juicio, "los Derechos Humanos [...] son violados hoy tanto como ayer; ya se trate de la época en la que el cristianismo empezaba a ejercer una influencia moderadora; ya de ciertas circunstancias históricas recientes, en las que se extendieron las concepciones declarativas que, a la postre, se han transformado en habituales. Las lesiones que padecen los Derechos Humanos sólo han cambiado en lo exterior [...]"2. Pero, y esto es lo relevante aquí, "esta verdadera y relevante 'tradición' de la injusticia", como la puntualiza el autor, acaece en lo más propio del ser humano, es decir, en su raíz, en "la parte menos jurídica de todas; la parte que, separada de una referencia a la naturaleza de las cosas e indiferente a las medidas relacionadas con la igualdad patrimonial, se somete a la naturaleza del hombre y que, independientemente de toda distribución de bienes, no considera sino a los Derechos Humanos nacidos de su propia humanidad"3.

Lo expuesto, que parece perceptible en un buen número de ejemplos -como, v. gr., los desafíos que proponen los desarrollos de las ciencias médicas, algunos de los cuales se examinarán en lo que sigue-, es lo que Trigeaud ha denunciado en su vasta obra y que exige abrogar la separación nacida de las perspectivas ya racionalistas, ya empiristas-voluntaristas (en definitiva, positivistas), que propiciaron la separación entre "naturaleza" y "persona" y una mirada antitética entre "cuerpo" y "alma", entre lo "espiritual" y lo "material"; entre la "vida íntima" y la "vida social" de todo ser humano contemporáneamente al uso $0^{4}$.

2 Trigeaud, J. M. (1993). "Derecho Natural y Derechos Humanos en los albores del siglo XXI. La tradición clásica del Derecho Natural y su superación por el personalismo". Persona y Derecho. $28^{\circ}$. Pamplona, 282 (el énfasis corresponde al original) (del francés por Renato Rabbi-Baldi Cabanillas).

3 Ibíd., loc. cit. En idéntico sentido, cfr. su obra (1992). Introduction á la Philosophie du Droit. Biére. Bordeaux, esp. 61. Sobre una síntesis de esa obra, cfr. la referida reseña de mi autoría publicada en (1995). Persona y Derecho. 30. Pamplona, 378-380.

4 Cfr. ibíd., esp. 286-296. Sobre el distingo entre "vida íntima y vida social” cfr. también las sugerentes reflexiones de Caliva, C.; Esses, M. "La capacidad en el nuevo Código Civil y Comercial de la Nación: sustrato filosófico y compatibilidad con las normas internacionales sobre la materia". En Rabbi-Baldi Cabanillas, R. (director). Los derechos de las personas en el nuevo Código Civil y Comercial. Aproximación a algunos aspectos novedosos. La Ley-Servicio de Publicaciones de la Facultad de Derecho, UBA, 91-93. 
En efecto, si se piensa en temas como el modo de generar vida a través de tratamientos de fertilización asistida (FIV), o bien por conducto de terceras personas (caso de la maternidad subrogada); la posibilidad de interrupción de la vida a través del aborto; los supuestos de experimentación en seres humanos; el tratamiento y consecuente disponibilidad (o no) de ciertas partes del cuerpo, tal el caso de las células madre o, como se verá en este papel, los criterios de selección del nacimiento de las personas por conducto de diagnósticos genéticos preimplantatorios (DGP), se advierte, sin mayor esfuerzo, que las personas viven, como escribió en su día Arthur Kaufmann, "riesgosamente"5; que la posibilidad de su "cosificación", para emplear una clásica expresión kantiana ${ }^{6}$, es relativamente sencilla y que, por ende, la temida violación de los Derechos Humanos es un hecho que, como previene Trigeaud en los textos más arriba citados, hace posible "pervivir en la injusticia". De ahí que, a su juicio, la misión de los Derechos Humanos debe orientarse "a la luz de una filosofía que los sitúa en la prolongación de la persona, de suerte de restaurar la unidad perdida y, a partir de la definición del hombre que ella propone, preservar sus riquezas fragmentadas y empobrecidas por la naturaleza y rehabilitar la diferencia radical de su individualidad, personal y espiritual y no empírica y subjetiva [...]”"?.

Pues bien, tras destacar algunas notas de su propuesta iusfilosófica (II), vincularé su tesis, como se adelantó, con aspectos relacionados a la bioética, en particular, el supuesto del Diagnóstico Genético Preimplantatorio (DFP) (III), antes de efectuar unas breves conclusiones (IV).

\section{Algunas notas de la filosofía jurídica "prosopológica" de Trigeaud}

El planteamiento del profesor de Burdeos concierne centralmente en dar cuenta del ser del hombre o, como él lo dice -en un signo, si cabe, de "distinción" y de "originalidad"-, del "prosopon", dando vuelta así un significado etimológico que, como es sabido, mienta exactamente lo contrario que

5 Kaufmann, A. "El renacimiento del Derecho Natural de la posguerra y lo que fue de él” (del alemán por A. Guardia Clausi). En Rabbi-Baldi Cabanillas, R. (2008). Las razones del Derecho Natural. Perspectivas teóricas y metodológicas ante la crisis del positivismo jurídico. Buenos Aires. Ábaco, 384.

6 Cfr. Kant, I. (1983). Fundamentación de la metafísica de las costumbres (del alemán por E. García Morente). Madrid. Espasa, 80 y sigs.

7 Ibíd., 295.

8 Cfr., entre otros, Introduction..., nota 3, esp. 11-13. 
su planteamiento ${ }^{9}$. No se trata, en efecto, de comprender la "máscara" que actúa en la vida social sino al "universal diferente", al "otro antes" ("autre d' abord"); finas expresiones que remiten a otra, tanto o más expresiva que las precedentes: al "diferente concreto"10.

La persona, pues, es una; única e irrepetible: ahí lo "diferente concreto"; pero la persona comparte su mismidad con el resto de los humanos: ahí lo "universal". De algún modo, la "gloria" de cada ser humano es también la del otro, en tanto todos comparten comunes exigencias y parejos bienes primarios. Pero conviene reparar que esa comunidad de exigencias y bienes no remite a una dimensión abstracta, sino que se perfila en las concretas circunstancias de todos y cada uno. De ahí esa idea nuclear de que la persona es el "autre d' abord": si no se reconoce, primariamente (antes que nada y en su radical identidad entitativa), al otro, no hay coexistencia posible y la idea de base de la universalidad se desvanece inexorablemente. Trigeaud, en efecto, es categórico: "[...] todo parte de la evidencia de ese valor absoluto (en razón de ser universal y no general o conceptual) que es el diferente concreto" y cuya defensa incumbe a la justicia en tanto se concibe "como la voluntad de reconocer, de respetar, de proteger a ese universal diferente, de acuerdo con los medios conceptuales que le ofrecerán el Derecho y la política"11.

Sobre tales bases, la filosofía jurídica prosopológica finca en el reconocimiento de la identidad personal. Se trata, dice Trigeaud, de un tema que se evade de lo meramente "positivo" (que en el autor se asocia con lo "fenoménico") para ingresar en lo "filosófico" (esto es, en la lógica de su pensamiento, en lo esencial), justamente ante, v. gr., "las dificultades advertidas por las manipulaciones genéticas o las amenazas que ponen a prueba las democracias, como el terrorismo o los conflictos armados inter-religiosos o inter-étnicos"12. De ahí que, retomando una apreciación ya adelantada en el apartado anterior, este asunto "pertenezca a una filosofía de la 'naturaleza del hombre', la que ha permitido llevar al Derecho -que se encontraba centrado sobre la 'naturaleza de las cosas'- a las exigencias de una ética social. Y este problema muestra, al mismo tiempo, el carácter indivisible de una reflexión sobre el sentido y sobre el fin del hombre en el Derecho: el deber ser (ought) no es escindible del ser (is)"13.

9 Sobre esto, cfr. Hervada, J. (1992). Lecciones propedéuticas de Filosofía del Derecho. Pamplona. Eunsa, 425-430, y nuestra (2019). Teoría del Derecho. Buenos Aires. Ábaco, 41-46.

10 Cfr. Introduction..., nota 3, esp. 11-17 o 68.

11 Ibíd., 68.

12 Trigeaud, J. M. (1993). "La identidad de la persona" (del francés por Renato RabbiBaldi Cabanillas). Anuario de Derecho de la Universidad Austral. Buenos Aires, v. 3, 1.

13 Ibíd., loc. cit. 
Desde esta perspectiva, "la identidad alcanza al ser personal como acto de vida y no como potencialidad. Ella connota, en fin, una dignidad adquirida que no tiene que 'realizarse' u 'obtenerse' a través de un devenir personal, al compás de las oportunidades que se le presentan en las relaciones nacidas al amparo del 'contrato social', ya que aquella no deviene nada distinto de lo que ya era antes, puesto que, de ocurrir esto último, esta 'dignificación' haría prevalecer la potencia sobre el acto, lo cual sería invertir el orden del ser"14.

La identidad, entonces, es a la vez universal y singular; emerge como una señal que hermana a todos y, también, como un dato que es de cada quien de modo intransferible. En cuanto a lo primero, la identidad "tiene a la vista el elemento inmutable o invariable que refleja la esencia de la existencia humana; ella alcanza lo inteligible en el hombre al asirlo en su integralidad (carne y alma)". A su vez, en cuanto a lo segundo, la identidad plantea que "lo propio de la universalidad es el abrirse a su referente: al reconocimiento de la singularidad [...] que entraña la identidad de la persona viviente y que, por lo mismo, es reconocida como tal; es objeto de 'tuteo' (tutoiement)"15.

Profundícese por un instante en el par universalidad-singularidad. Como expresa Trigeaud, muchos de los retos bioéticos antes señalados "han desmantelado la integralidad bio-psíquica del hombre", por lo que "el lenguaje de la particularidad sustituye al lenguaje de la singularidad o de la alteridad ontológica radical".

Sin embargo, en cuanto respecta a la singularidad, cabe reparar que, en sus orígenes, "esta voz es empleada a fin de designar el entero o el todo ser humano, en la irreiterabilidad o la unidad existencial de su acto de vida"16. De ahí que sea interesante advertir que semejante es la percepción que hoy se tiene del ser humano a partir de los aportes que proporciona la genética más sofisticada a propósito, v. gr., de los gemelos monocigóticos.

En efecto, como se pone de relieve en un caso resuelto por la Cámara Federal de Apelaciones de Salta, la posible divisibilidad del embrión que, en determinadas circunstancias, da lugar al fenómeno recién descripto, nada dice contra la individualidad (la "singularidad", en los términos de Trigeaud) de los gemelos, quienes si bien son genéticamente idénticos, resultan, como es bien perceptible, dos personas enteramente distintas, portadoras de diversos "actos de ser" que los caracterizan de modo radicalmente diverso entre sí y respecto de terceros ${ }^{17}$.

14 Ibíd., 14. Cfr., también, 18.

15 Ibíd., 14.

16 Ibíd., 15.

17 Cámara Federal de Apelaciones de Salta, República Argentina, causa "R. N. F. c/ Obra Social del Poder Judicial de la Nación s/ amparo", sent. del 3-9-2010, voto del juez RabbiBaldi Cabanillas, LLNOA, noviembre de 2010, p. 991; JA, Buenos Aires, t. 2010-IV, p. 72. 
El supuesto recién referido, sumamente sugerente en cuanto permite mostrar con toda claridad la profunda dimensión de la unidad biológica, de un lado, y de la diversidad espiritual, de otro, que acompaña en ciertas circunstancias al ser humano, conecta con provecho con lo que Trigeaud mienta como la "experiencia integral de una diferencia"18.

En este horizonte, considera Trigeaud que frente a la disociación, producto de los planteamientos teóricos referidos en el anterior apartado, "la identidad de la persona viviente puede ser de nuevo concordada, como fundamento de una dignidad constituida [...] para inspirar una protección o un respeto -primero ético, después jurídico- sin el cual el respeto a las soluciones que ofrece el Derecho no es, ni siquiera, 'respetable' o absolutamente justificado"19. Y añade: "[...] el problema del Derecho reside en no poder transformar enteramente esta identidad de característica metafísica y ética en una identidad precisamente jurídica, toda vez que la primera identidad es absoluta, mientras que la segunda que implica la anterior, es necesariamente relativa". El Derecho, observa Trigeaud, en tanto ámbito de lo "tuyo" y de lo "mío", puede, de ordinario, no asir conductas como el "perdón" (negando de esta manera el principio jurídico de responsabilidad) o la "dación" (negando así el principio jurídico de la propiedad). Empero, "aquello que, precisamente, en supuestos como los recién examinados, lo hace 'justo' y 'obligatorio' [a ese perdón o esa dación -piénsese, v. gr., en los trasplantes de órgano], reside en el hecho de no conculcar una capacidad singular y eminentemente personal de ser singularmente (y no colectivamente)"20. De esta forma, "la identidad de la persona en el Derecho puede valerse de una identidad más amplia y completa, de carácter ético, que la sitúa en la dimensión del mejor ideal del hombre [...]". En definitiva, "la identidad es el signo de una dignidad que se adquiere a pesar de que pueda no merecérsela, toda vez que se la posee por el simple hecho de ser un existente humano"21.

18 Trigeaud, J. M. "Derecho Natural...”. Ob. cit., nota 2, 298.

19 Trigeaud, J. M. "La identidad...". Ob. cit., nota 12, 18.

20 Ibíd., loc. cit.

21 Ibíd., 18-19. De modo análogo, D’ Agostino, F. (1991). "Il principio familia come criterio bioético fondamentale". En Linee di una Filosofia della Famiglia nella prospettiva della filosofia del diritto. Giuffré, 163-164 y 167, considera que la identidad es lo que da sentido a la realidad del Derecho. A su juicio, éste no puede sino aspirar a "ser la estructura de la protección y de la promoción de la identidad de la persona", toda vez que "el principio jurídico fundamental de nuestro tiempo reside en el reconocimiento, en todo ser humano, de un sujeto jurídico". Por ello, continua el autor en clara sintonía con el pensamiento de Trigeaud, si se piensa en el ámbito de la bioética, parece claro que ninguno de sus descubrimientos, desarrollos y, especialmente, procedimientos, deberían afectar, de principio, esto es, "no como un axioma, sino como un arché", la "posibilidad del reconocimiento de la identidad del individuo humano". 
Desde esta lógica cobra todo sentido la propuesta trigeaudiana de una reflexión filosófica del Derecho anclada en la concreción de lo que él denomina "dikelogía". Esta "idea de la justicia", como se señaló en otro lugar, no puede asociarse a la "idea de Derecho" de sabor neo-kantiano, pues apunta a algo que se encuentra en el ámbito de la realidad más tangible y, precisamente por ello, se encuentra revestido de un máximo contenido: el indisponible respeto a la persona que se hace patente, como se anticipó, ante la "tradición de la injusticia" 22 . Es que no es posible disociar "persona humana y valor de justicia" 23 , ya que no cabe una reflexión que no traduzca "la realidad profunda de la experiencia vivida" por el ser humano, sea ésta de la índole que sea (dramática o virtuosa), contrariamente a las perspectivas positivistas-empiristas (cientificismos, sociologismos, funcionalismos) y racionalistas, las que, en tanto "se limitan a definir y a desarrollar conceptos enteramente provenientes de la razón" 24 , quedan huérfanas de respuesta ante ese aspecto crucial de la realidad de la vida que impacta de lleno sobre la del Derecho.

Y esta omisión es determinante en el ámbito de la bioética pues aquí, como su propio nombre lo indica, se está ante un debate de índole -precisamente- ético, esto es, de contenido; de proposiciones sobre lo justo y lo injusto; sobre lo mejor, lo menos malo o lo peor (que en términos de la casuística constitucional se advierte cuando en la tensión entre derechos constitucionales se producen equilibrios "óptimos"; "mínimos" o "dilemas" en cuanto a la concreción de los derechos fundamentales ${ }^{25}$ ), "a menos de optar por una aproximación 'meta-ética', 'no cognitivista', cuantitativista y materialista, de acuerdo con la cual no se hará más que administrar las opiniones irracionales y dominantes, financiadas por el más fuerte"26. En esta última perspectiva, concluye el autor, la aparición "empírica de una persona es equivalente a la aparición de una cosa", de suerte que ésta "no es más que un medio ordenado a los fines que se le ha escogido para ella y que no tiene sino que aceptar de buen grado"27.

22 Ibíd., 13 y sigs.; "Derecho Natural...”. Ob. cit., nota 2, 281-282.

23 Trigeaud, J. M. (2017). "La personne n'est pas un 'projet'. Réponse éthique et juridique au Pr Axel Kahn á propos de la naissance d' un 'bébé médicament". En Métaphysique personanliste. Biére. Bordeaux, 203.

24 Trigeaud, J. M. Introduction ..., nota 3, 17. Cfr., asimismo, "La identidad...”. Ob. cit., nota $12,15-17$.

25 Cfr. a partir de los planteamientos de Dworkin, Alexy y Atienza, mi Teoría del Derecho, nota 9, 373-378.

26 Trigeaud, J. M. “La personne...”, nota 23, 203.

27 Ibíd., 203-204. 


\section{Aplicación de la iusfilosofía "prosopológica" al ámbito de la bioética: el caso del DGP}

Con la precedente reflexión se abre camino la tercera y última parte de este papel. Trigeaud efectúa dicho comentario a propósito del advenimiento de los denominados "bebés de diseño". A su juicio, "después de la esclavitud de los servicios feudales de los que se liberaron el asalariado moderno y el contrato de trabajo, podría bien instaurarse una nueva esclavitud, esta vez de carácter genético e intra-familiar [...] porque se niega que la persona significaría una libertad propia o autónoma; que ello puede designar el asiento mismo de toda su dignidad; y se insinúa como aceptable la idea de poder mercantilizar o cosificar la vida humana (al hacerlo un bien privado de vocación intrínseca, una res extensa cartesiana...)"28.

$\mathrm{El}$ autor, en efecto, reflexiona a propósito del caso de un niño nacido mediante técnica FIV a fin de salvar a su hermana, gravemente afectada por una enfermedad (beta-talasemia). Al respecto, repara en la opinión de un genetista quien, si bien rechaza que a través de dicha práctica se favorezca algún tipo de control eugenésico o que los padres puedan determinar anticipadamente el sexo del niño, considera que aquélla está "inspirada por la ética más alta: ayudar al otro", maravillándose de que "el sentido de un deber de asistencia o de solidaridad haya acompañado los prodigiosos progresos de la medicina y de la genética entregándoselos al bien de las personas y de la sociedad"29.

Con todo, Trigeaud presta especial atención a cómo el recién citado caracteriza al recién nacido, a quien su familia, de origen turco, ha llamado Umut-Talha ("Esperanza"): éste es una "persona, es decir, un sujeto libre e independiente", pero también es "un proyecto"; es, según el señalado especialista, "una persona en tanto que proyecto", con lo cual, concluye Trigeaud, "se desliza un elemento relativo dentro de la estructura absoluta de la persona". Es que "la palabra 'proyecto' traduce [...] la idea de acuerdo con la cual [...] una dirección mayor del sujeto personal ya no le pertenecería verdaderamente más como propia, sino que sería recibida por él desde el exterior y le sería por tanto conferida desde allí o por aquellos que le dieron la vida" 30 . A juicio de Trigeaud, la afirmación precedente no va sin objeciones: el autor plantea las siguientes.

28 Ibíd., 204.

29 Ibíd., 205.

30 Ibíd., loc. cit. 
a) Observaciones de índole psicológica. Una de ellas se ubica "en el plano elemental de la psicología", ya que, si el "proyecto" no prosperara, el recién nacido "debería asumir un sentimiento de culpa que su familia o la sociedad podrían recordárselo. Y la idea de que, en definitiva, él no haya nacido más que para alcanzar un logro funcional, desequilibraría en profundidad su percepción psicológica y afectiva de familia, ya que él no se encontraría en un plano de igualdad, sino dependiendo [...] de la mirada o de la función asignada por los otros" 31 .

b) Observaciones de naturaleza filosófica. Una segunda objeción se ubica en el nivel filosófico y concierne a la definición de persona ensayada por el genetista. Ella, es claro, "conduce a profesar la idea de que la persona es más potencia que acto y que puede devenir lo que no es todavía [...]". Pero si como se anticipó en los puntos precedentes, "la persona 'es', es a fin de poder devenir aquello que ella es, sin que su ser, comprendido en la universalidad e incondicionalidad de su verdad existencial, obstaculice su libertad. Desde entonces, su fin es el de realizar el acto que informa su misma existencia y que es capaz de actualizar todas las potencias inscriptas en su naturaleza, una naturaleza que no es sino materia pasiva en relación con su acción"32. En ese plano, "en el corazón mismo del acto de existir, que denota (avére) la singularidad de cada uno, se sitúa armónicamente la libertad. Es en esta perspectiva que la libertad caracteriza la persona e indica su vocación a no depender más que de ella misma y de sus elecciones", dentro de las cuales se dan cita, por ejemplo, "las opciones que son susceptibles de guiarla, por lo demás, a los actos más gratuitos que renuncian a toda contraprestación; actos que reflejan precisamente su personalidad última [...]". En ese horizonte, concluye el autor, "si la persona es valor [...] ningún fin o valor del hombre que implica su naturaleza y todos los elementos recibidos de ella puede ser considerado como ético si ella no respeta íntegramente la libertad de la persona que debe poder decidir por sí misma. De lo contrario, la persona existiría 'en otro' y no en ella, y ese in aliud sería la marca de una alienación al que no podría sustraerse [...]"33 y que vendría causada por la razón de ese origen instrumentalizado por un determinado propósito.

c) Observaciones de índole jurídica. En efecto, desde esta última perspectiva, Trigeaud escribe que "el recién nacido es una persona jurí- 
dica, y bajo este título, disfruta de un derecho que el tiempo no hará más que desarrollar respecto de sus libertades civiles y públicas", lo cual "engloba, sin límite, de la esfera de sus decisiones, las más discrecionales. Dicho en otros términos, él no es más el objeto de un derecho real [...]"34. Si lo recién expuesto es tomado en su radicalidad, entonces la práctica en análisis queda comprometida de raíz. Trigeaud así lo concluye, cuando expresa que "la extracción del cordón será interpretada como una autorización de su voluntad a perseguir un acto reportado sobre sí mismo", lo cual, añade, "no puede sino contradecir la imposibilidad de admitir en Derecho Civil el carácter implícito de los actos abdicativos". Es que "no se puede a fortiori disponer de una parte regenerable o no de su cuerpo, de manera evidentemente gratuita, sin que se hubiera expresamente consentido" 35 . Todo ello, en fin, parece indicar que "la lógica latente de esta concepción de conjunto es claramente la de la mercantilización, que sustituye en la persona humana su valor de utilidad para los otros, a su valor en sí misma y por sí misma"36.

Y, concluye el autor, que no cambia las cosas que -como se argumenta- esta práctica no supone ningún atentado contra el recién nacido, "ya que sólo son utilizados el cordón y la placenta", puesto que lo realmente significativo es la concepción de fondo sobre la que reposa, esto es, la idea de "persona-proyecto" antes mentada. Es que "si la persona no es más que un ser potencial antes que un ser real [...] y si ella goza de una cierta libertad, eso que ella será mañana y eso que se acordará que devenga podría conformarse a fines que ella no eligió y que le son impuestos según el modelo ético [...] que le asignan indirectamente sus progenitores" 37 . Se está, pues, ante una "instrumentalización que concierne ciertamente al ser humano, sujeto de Derecho, pero que no cesa de concernir al Derecho entero cuando se trata de vincularlo a simple medios formales" 38 .

\section{Conclusiones}

De cuanto se lleva dicho, creo advertir, a guisa de conclusión de estas reflexiones que constituyen aleccionadores llamados de atención en orden

34 Ibíd., 209.

35 Ibíd., 209-210.

36 Ibíd., 210.

37 Ibíd., 209-210.

38 Ibíd., 210. 
a que la defensa y el progreso del ser humano no entrañe, concomitante, su propio debilitamiento o, incluso, su misma anulación, lo que redundaría en refutar el objetivo deseado. Se trata de un desafío que, v. gr., los formidables desarrollos de las ciencias médicas y de la genética-aquí sucintamente mencionados- interpelan a la humanidad casi a diario. En este campo, es claro, los cambios son constantes; las respuestas, dinámicas y, por tanto, siempre provisorias. Empero, en todas estas circunstancias el límite (y también, forzoso es señalarlo, el punto de partida) no parece ser otro que la indisponibilidad de la persona 0 , como escribe Trigeaud y fue citado más arriba, ese "valor absoluto (en razón de ser universal y no general o conceptual) que es el diferente concreto" (cualquiera sea su posición y relevancia fáctica, especialmente si ésta es insignificante) y cuya defensa incumbe -como lo muestran los casos de especie aquí examinados-, para recordar el planteamiento del profesor francés, la actuación conjunta y constante tanto de la “dikelogía" (lo justo jurídico), cuanto de la "polilogía" (lo justo político) ${ }^{39}$.

\section{Bibliografía}

Cámara Federal de Apelaciones de Salta, República Argentina, causa "R. N.F. c/ Obra Social del Poder Judicial de la Nación s/ amparo", sent. del 3-9-2010, voto del juez Rabbi-Baldi Cabanillas, LLNOA, noviembre de 2010, p. 991; JA, Buenos Aires, T. 2010-IV, p. 72.

D’ Agostino, F. (1991). "Il principio familia come criterio bioético fondamentale". En Linee di una Filosofia della Famiglia nella prospettiva della filosofia del diritto. Giuffré.

Hervada, J. (1992). Lecciones propedéuticas de Filosofía del Derecho. Pamplona. Eunsa, 425-430.

Kant, I. (1983). Fundamentación de la metafísica de las costumbres (del alemán por E. García Morente). Madrid. Espasa, 80 y sigs.

Kaufmann, A. (2008). "El renacimiento del Derecho Natural de la posguerra y lo que fue de él" (del alemán por A. Guardia Clausi). En Rabbi-Baldi Cabanillas, R. Las razones del Derecho Natural. Perspectivas teóricas y metodológicas ante la crisis del positivismo jurídico. Buenos Aires. Ábaco, 384.

Rabbi-Baldi Cabanilla, R. (2019). Teoría del Derecho. Buenos Aires. Ábaco.

Trigeaud (1993). "La identidad de la persona" (del francés por Renato Rabbi-Baldi Cabanillas). Anuario de Derecho de la Universidad Austral. Buenos Aires, v. 3, 13.

Trigeaud (2017). “La personne n'est pas un 'projet'. Réponse éthique et juridique au Pr Axel Kahn á propos de la naissance d' un 'bébé médicament". En Métaphysique personanliste. Biére. Bordeaux.

39 Trigeaud, J. M. Introduction..., nota 3, 86. 